\title{
Almanzor: drama histórico de Blas Infante
}

\section{Almanzor: Blas Infante's Historical Drama}

\author{
Josep Esquerrá Nonell \\ Universidad de Kragujevac (FILUM)
}

\section{RESUMEN}

La reciente publicación de una obra de teatro inédita y original de Blas Infante: Almanzor, drama histórico incompleto escrito hacia la primera mitad de los años 20 del siglo pasado, abre posibilidades de interpretación con respecto a otra obra escrita en el mismo periodo, La Dictadura Pedagógica, con una finalidad clara de superación de la España de la Restauración desde el punto de vista histórico. Almanzor es además su segunda obra de temática andalusí, junto con Motamid, último rey de Sevilla. La obra es, principalmente, una adaptación de la Historia de los musulmanes de España hasta la conquista de los almorávides de R. P. Dozy. Pertenece a la modalidad dramática que el Modernismo denominó teatro poético, pero la obra tiene una honda raíz romántica. Infante recrea, una vez más, el glorioso pasado de Al-Ándalus.

Palabras Clave: Blas Infante, Almanzor, Andalucía. Restauración, drama histórico, teatro poético, Modernismo, inspiración romántica.

\begin{abstract}
The recent publication of an unpublished and original theatre play by Blas Infante: Almanzor, an unfinished historical drama written in the early 20's of the last century, opens up possibilities of interpretation in relation to another work written in the same period, The Pedagogical Dictatorship, that has a clear intention of improving the Spain of the Restoration from a historical point of view. Almanzor is also his second play with an Andalusian theme, along with Motamid, the Last King of Seville. The play is primarily an adaptation of the History of the Muslims of Spain until the Conquest by the Almoravids of R.P. Dozy. It belongs to the dramatic form coined as poetic theater by Modernism, but the play has deep romantic roots. Infante once again recreates, the glorious past of Al-Andalus.
\end{abstract}

Key words: Blas Infante, Almanzor, Andalucia, Restoration, historical Drama, Poetic, Theatre, Modernism, Romantic inspiration.

Nuestro conocimiento acerca de la producción dramática de temática andalusí de don Blas Infante Pérez de Vargas (1885-1936), máximo exponente del nacionalismo histórico andaluz del siglo $\mathrm{XX}$, se había limitado hasta el momento presente a una sola obra publicada en 1920, bajo el título de Motamid, último rey de Sevilla. No obstante, ha permanecido inédito un segundo drama histórico original del autor y del que prácticamente nada se ha dicho, 
Almanzor, obra que acabo de publicar recientemente (Infante, 2012) ${ }^{1}$. Se trata de una pieza teatral inacabada, puesto que sólo conservamos completa la jornada $1^{\mathrm{a}}$, una parte escasa de la jornada $2^{\mathrm{a}}$ y una fracción del prólogo, con el objeto de poder ofrecer, hasta el momento (pese al carácter fragmentario de la obra dispersa en una constelación de manuscritos, ya que carecemos aún de una edición que comprenda la problemática inclusión y engarce con las otras casi dos terceras partes de la misma), una lectura lo más completa posible del drama histórico que nos ocupa.

He podido realizar dicha labor de reconstrucción gracias a la edición digitalizada de los documentos de la colección «Manuscritos de Blas Infante», llevada a cabo por el Centro de Estudios Andaluces de Sevilla, entre los cuales se encuentra el Manuscrito Almanzor (AAZ), dado que además «la versión AAZ parece la que Infante consideró definitiva», según Iniesta CoullautValera (1989: 43). A continuación transcribo la siguiente descripción que el Padre Enrique Iniesta hiciera sobre este importante manuscrito:

AAZ: 235 páginas. Serie de cuartillas de medida grafía, copia de un manuscritoborrador (perdido); es el original del drama «Almanzor». Está incompleto; incluye íntegra la «jornada I», se interrumpe bruscamente la segunda jornada de la que sólo aparecen las primeras páginas, en la 222 y siguientes. Debe advertirse que esa «primera jornada» tiene entidad por sí misma. Tema: Histórico, aunque no crítico, lo que no quiere decir que carezca de documentación muy seria. Descripción de la Córdoba de la etapa de Hixén II. Muy relacionado con los manuscritos ABD, AEP, ADÑ y ADO (Iniesta Coullaut-Valera, 1989: 34)2.

Resulta cuanto menos extraño que, al término de su libro La Dictadura Pedagógica (1921) —escrito bajo el poderoso influjo de la revolución rusa que en noviembre de 1917 había establecido el primer gobierno obrero y campesino de la Historia, hecho frente al cual Infante se muestra clarividente al intuir el papel excluyente y déspota de la burocracia y el ejército-, se incluya un catálogo o repertorio de otras obras publicadas por el autor en la misma colección, así como otras que se anuncian como de próxima aparición, entre las que se halla, y cito textualmente, tal como se encuentra bajo su título arabizado: Al Mansur ${ }^{3}$. Y digo esto porque hemos de suponer, en consecuencia, que

\footnotetext{
${ }^{1}$ Esta versión que ofrezco está hecha a partir de los manuscritos AAZ y ADÑ. Solamente se había publicado hasta el momento algún pequeño pasaje disperso, vid. Iniesta CoullautValera, 1998. El autor publicó aquí una frase suelta del Manuscrito Almanzor (AAZ,128), así como un breve fragmento (AAZ, 206-208); manuscrito designado como $A A Z$, según su propio criterio de catalogación.

${ }^{2}$ Por lo que respecta al Manuscrito $A B D$ incluye un texto que acabará fijado en el AAZ, vid. Iniesta Coullaut-Valera (1989: 34).

${ }^{3}$ Véase al respecto, Infante (1921), última página no numerada. En el ejemplar de esta edición que se encuentra en la Biblioteca de Cataluña en Barcelona, se encuentra, por cierto, una interesante dedicatoria manuscrita y firmada por el autor dirigida a Ramón Franco, hermano del General Francisco Franco y que dice así: «A Ramón Franco a quien ha discer-
} 
Blas Infante estaba ultimando o preparando por aquel entonces la que iba a ser una de sus próximas publicaciones; sin embargo, lo cierto es que habría de permanecer inédita hasta este mismo año en que me he propuesto rescatarla del olvido. Podría alegarse que la situación política pudiera haber incidido negativamente, tanto a raíz del denominado «Desastre de Annual» (julio de 1921) — por lo que quizás su Al Mansur (cast. El Victorioso) hubiera podido interpretarse torcidamente como una apología encubierta del caudillo rifeño Abd el-Krim El Jatabi-, como a partir del golpe de estado del General Miguel Primo de Rivera en 1923; pero lo cierto es que tampoco desde el establecimiento de la Segunda República el autor se decidió a publicarla, bien porque abandonara el proyecto de su pieza dramática, por razones que ignoro, o ya por sentirse desbordado por los acontecimientos de su agitada vida política. Sea como fuere, lo cierto es que todo lo que rodea a su drama histórico Almanzor encierra más de un enigma.

Dado que hemos de tener presente en todo momento que partimos de un manuscrito plagado de tachones y con pasajes harto oscuros con letra minúscula, y que presenta, por tanto, no pocos interrogantes que ha habido que resolver, la labor de transcripción ha resultado dificilísima en ocasiones, tomando como referencia el ya citado Manuscrito Almanzor (AAZ) ${ }^{4}$, así como también el Manuscrito Alegorías. Génesis (ADÑ) ${ }^{5}$ que contiene parte del drama Almanzor con numerosos pasajes repetidos, variantes y el prólogo mismo de la obra, que he logrado recomponer del modo más fiel posible. Todo esto ha de servirnos, en definitiva, para fijar una primera edición del texto apta para su lectura y estudio posterior ${ }^{6}$. No otro fue mi propósito.

nido la naturaleza, el dolor y la gloria de haber de dirigir el vuelo soberano de España, hacia un más allá indefinido, y del cual vuelo fue símbolo profético, el del Plus Ultra: Estos escarceos de la juventud de su afcmo. B. Infante».

${ }^{4}$ Manuscrito Almanzor (AAZ), digitalizado por el Centro de Estudios Andaluces de la colección de manuscritos de Blas Infante [en línea], Junta de Andalucía, Sevilla, http:// maa.centrodeestudiosandaluces.es/biblio/imagendoc/00007001_00007500/00007347/ 00007347_090h0101.PDF , [Consulta: 10.01.2012], cuyo original se encuentra en el Archivo personal de la Casa Museo de Blas Infante.

${ }^{5}$ Manuscrito Alegorías. Génesis (ADÑ), digitalizado por el Centro de Estudios Andaluces de la colección de manuscritos de Blas Infante [en línea] , Junta de Andalucía, Sevilla, http://centrodeestudiosandaluces.es/biblio/imagendoc/00006501_00007000/00006911/ 00006911_090h0101.PDF ,[Consulta: 9.02.2012], cuyo original se encuentra en el Archivo personal de la Casa Museo de Blas Infante. $C f$. Iniesta Coullaut-Valera (1989: 43). En esta misma página Iniesta describe también cómo en el Manuscrito ADO de 70 páginas se encuentran, entre otras: «Conjunto de notas para el drama Almanzor: históricas (1-11, 27-30), litúrgicas (31-70), musicales (4), lexicales (4-7, 10, 23-25) y hasta gráficas $(4,6,8,10,24)$. En algunos casos redacta pasajes en su forma literaria $(2-4$ - ien verso! - 12, 14, 17, 19, $21,22) »$. Dicho manuscrito al no estar digitalizado y resultar de difícil acceso, no me ha sido posible incorporarlo a mi edición, si bien ya poseo copia del mismo, gracias a la Fundación Blas Infante y la confianza que en mí ha depositado.

${ }^{6}$ No me ha sido accesible consultar todavía el Manuscrito AEP al no estar digitalizado pese a su importancia significativa, motivo por el que mi primera edición se verá ampliada 
Ciertamente, hemos de movernos en torno a 1918-1919 para comprender el viraje ideológico experimentado en el pensamiento de Blas Infante, desde su georgismo inicial de 1913 y el andalucismo medioburgués de 1910, hasta el planteamiento de sus decididas tesis nacionalistas, iniciado ya a partir de la fundación de los Centros Andaluces (1916) y, muy especialmente, de las Asambleas de Ronda (enero 1918) y Córdoba (marzo 1919). Su primer libro, El Ideal Andaluz (1915), habría ya de contener bajo la forma de regionalismo, el germen vivo de su incipiente nacionalismo y el punto de inflexión de su progresivo alejamiento de la burguesía media ${ }^{7}$. Posteriormente, frente al «Principio de las Nacionalidades», mediante el cual se define la nación, como ente político, ante todo, por la existencia histórica de un Estado, Blas Infante opondrá la idea del «Principio de las Culturas», por el que los pueblos no son entes políticos, sino culturales, todavía más en el caso de Andalucía ${ }^{8}$. Y es así como Infante, en su búsqueda de la cultura como fundamento de Andalucía, volverá la mirada hacia el glorioso pasado de Al-Ándalus, actualizando

y revisada con una segunda, gracias, de nuevo, a la Fundación Blas Infante que me ha concedido una copia de dicho manuscrito, teniendo en cuenta, sobre todo, las aportaciones que contiene, de acuerdo a la descripción de Iniesta: «AEP: 210 páginas. Cuartillas manuscritas. Numeradas originariamente de forma irregular, quedan paginadas de la 1 a la 210. Tema: «Almanzor». Se trata de un paralelo y complementario del AAZ y su constelación de manuscritos. (Véase ADÑ). De la página 1 a la 75, una descripción como onírica de la arquitectura romántica compostelana en clave apocalíptica. De la 76 a la 85 , una escena en un castillo de Braganza que incluye una descripción de la vida cordobesa en el siglo XI. Desde la 86 a la 95, notas sobre arquitectura, ritos mozárabes y armaduras militares medievales, todo ello proveniente de bibliografía que no cita. De la 102 a la 171, primera redacción de la jornada II del drama «Almanzor». De la 172 a la 210, buena parte de la jornada III y última de esa misma obra inédita» (Iniesta Coullaut-Valera,1989: 48).

7 Véanse al respecto las palabras de Infante (1976: 122), afirmando lo siguiente: «Yo tengo clavada en la conciencia, desde mi infancia, la visión sombría del jornalero. Yo le he visto pasear su hambre por las calles del pueblo, confundiendo su agonía con la agonía triste de las tardes invernales; he presenciado cómo son repartidos entre los vecinos acomodados, para que éstos les otroguen una limosna de trabajo, tan sólo por fueros de caridad» .

${ }^{8}$ Así es como Infante declaraba lo siguiente (Infante, 2008: 126-128): «Andalucía fue siempre un pueblo cultural, creador de las culturas más intensas y originales de Occidente. Fue siempre un pueblo antibélico y acogedor. En su territorio, siempre que fue libre (la última vez, durante la época musulmana), se operaron las grandes síntesis, prácticas o industriales, y doctrinales y científicas, de Europa. [...] En Europa está vigente el bárbaro principio de las nacionalidades, comodín que viene a justificar la rapacidad de los Estados; las salvajes exclusiones determinantes del nacionalismo (nación es para ese principio, un mero pretexto o justificación del Estado); y, en Andalucía, que no es Europa, que es Europa y África (en el secundario la Penibética formaba con África una unidad, hasta el Atlas: esa unidad natural no se ha roto, ni puede romperse por ser natural; a pesar de que se hayan quebrantado o disuelto las correspondencias unitarias políticas, morales y sociales, que en otros tiempos vinieron a expresar la existencia de un solo país), por haber sido pueblo cultural, no puede llegar aquel principio a alcanzar una vigencia rectora del ánimo de las gentes. Nuestra historia ha estado regida y continuará siendo regida por el Principio de las Culturas, no esencialmente político o excluyente, sino humano y universalista». 
lo mejor de sus inspiraciones esenciales de una forma totalmente nueva, y como primer renacimiento en Europa. A este respecto, se adaptan muy bien las palabras de Giuseppe Sergi, en la medida en que nos obligan a reflexionar sobre el concepto de Edad Media y la plasmación literaria que hará Blas Infante de la misma, a fin de encauzar su visión ideal de la Andalucía musulmana:

También a la instrumentalización de la Edad Media como «premisa» hay que atribuir el recurso a los siglos premodernos para buscar las «raíces»o la fase constitutiva de identidades nacionales, regionales o locales. En polémica con el universalismo dieciochesco y con el internacionalismo del siglo XX (buscado tanto en el capitalismo avanzado como en el llamado socialismo real), nacionalismos grandes y pequeños, correspondientes a culturas consolidadas o reinventadas para la reivindicación política, encuentran en la Edad Media «imaginada» (fraccionada y confusa, que ha dejado de ser romana y aún no está encuadrada en los grandes estados modernos) el espacio ideal para colocar tradiciones especiales, míticos orígenes, anticipos de identidades étnicas, nacionales o incluso regionales (Sergi, 2001: 23).

En 1920 Blas Infante habría de componer su tragedia Motamid, verdadera recreación del alma andaluza como pueblo. La obra consta de tres jornadas y un epílogo final. Infante lleva a escena los últimos años de la vida del Rey-Poeta, Muhammad ibn 'Abbad al-Mu'tamid, Rey de la taifa de Sevilla (1069-1090). Para el dramaturgo malagueño, la figura poética del Rey Al$\mathrm{Mu}$ 'tamid viene a restablecer el viejo espíritu andaluz de la Bética helénica ${ }^{9}$, contraria al racionalismo romano y luego francogermánico, en una sucesión de estilo que arranca desde la antigua Tartessos. La taifa de Sevilla contiene en sí las esencias de la Andalucía antibélica y cultural que se rige por normas de convivencia, respeto, democracia y conciencia libre, frente al fanatismo de los bárbaros invasores norteafricanos y castellanos que amenazan su existencia como reino. Blas Infante defiende además el papel rector de los intelectuales en la sociedad para llevar a cabo la regeneración espiritual de Andalucía, tal como se adivina en la voz del consejero del Rey-Poeta que viene a traslucir el pensamiento del propio autor:

No hay pueblo en el cual no exista muchedumbre. En todo pueblo, la minoría es el pueblo, la mayoría es la muchedumbre, sin conciencia. Y, a la muchedumbre, la fuerza organizada le parece augusta, cuando la potencia de esta fuerza es superior a su potencia inconsciente. La muchedumbre es como el agua que, no pudiendo romper el dique, discurre esclava por el cauce que viniera a abrirla, un organizado poder (Infante, 1983b: 30).

${ }^{9}$ No por otra razón afirmaba Infante lo siguiente (Infante, 1983a: 313): «Andalucía, de alma griega, incendiada a veces por orientales esplendores, repugna el exotismo y la extravagancia y ama el ritmo, hasta el punto de quererlo traducir aún en el andar del pueblo» (Publicado en la revista Andalucía, n. ${ }^{\circ}$ 174, año V, Córdoba, 6-I-1920). Se trata del único artículo literario de Blas Infante, cuyo contenido gira en torno a las vanguardias y su repercusión en la lírica andaluza, más concretamente en torno al Ultraísmo y la recién aparecida revista Grecia (Sevilla-Madrid), si bien el autor se muestra crítico con las últimas tendencias. 
Esta pieza dramática debía de haber tenido en el tiempo una continuidad con una segunda obra de inspiración similar: Almanzor, pese a que su autor la dejó inconclusa y no sólo no se decidió a finalizarla sino, menos aún, a editarla. Acerca de esta obra, conviene traer a colación de nuevo, las palabras del difunto Padre Enrique Iniesta al ser uno de los pocos testimonios que nos la han descrito:

En fecha aún no fijada produce un segundo drama de calidad y agilidad, hoy inédito (Manusc. AAZ, 234 págs.) y también de tema andalusí: Almanzor en el que manifiesta un conocimiento exhaustivo de la Historia del Califato, su arquitectura, arte del mueble y vestido. Entre sus escritos es continua la presencia de la lengua y la etimología árabes (Iniesta Coullaut-Valera, 1981: 43).

Como ya he expresado anteriormente, todo parece indicar que hacia 1921, Blas Infante estaba inmerso en el proceso de creación de su segundo drama histórico: Almanzor. Es muy probable que la obra inacabada fuera de similares proporciones que Motamid, teniendo en cuenta la jornada primera que conservamos completa. Consta de nueve pasajes de desigual duración, mientras que de la jornada segunda sólo conservamos una larga introducción inicial que sirve de ambientación histórica a los pasajes sucesivos que, por desgracia, no conservamos en su totalidad. La acción se desenvuelve en la Córdoba califal de finales del siglo X y es, mayormente, una adaptación literaria inspirada en la historiografía decimonónica escrita por el arabista holandés Reinhardt Pieter Dozy, más concretamente, de su obra cumbre, titulada: Historia de los musulmanes de España hasta la conquista de los almorávi$d e s^{10}$. Sirva a guisa de ejemplo ilustrativo, el pasaje en el que el alcaide Ben Okba relata el siguiente episodio sobre la personalidad de Almanzor:

Ben Okba: [...] Un día, comíamos juntos, en el huerto de un convento cristiano; de esos que venden vinos y sirven comidas a las gentes. Estábamos cinco estudiantes de leyes, incluyendo al Amir. ¿En qué piensas, le pregunté yo? Y, él, respondió con firmeza: - ¡En que yo seré un día el Carim, o Rey del Ándalus! Todos nos echamos a reír. Pero, Mohamed, muy serio, continuó: -En el día en que yo reine, os daré a cada uno de vosotros, el cargo que ahora me pidáis. Uno de los compañeros dijo: - Me agradan mucho estos buñuelos. Me nombrarás inspector de los mercados, y así podré comer cuantos quiera, tan ricos como éstos lo son...Otro, agregó: - Yo soy entusiasta de los higos malagueños. Me nombrarás Cadí $^{11}$ de aquella comarca... El tercero, habló a su vez: — Soy admirador de

${ }^{10}$ Acaso Blas Infante pudo servirse de la versión española de 1920, tomo III , en la traducción del francés por Magdalena Fuentes. No obstante, la primera traducción en cuatro tomos en $8^{a}$ fue la realizada por Federico de Castro, Sevilla: Biblioteca científico-literaria, 1877. Esta última parece la más probable que utilizara para su primer drama, Motamid, dado que también se inspira en la Historia de Dozy.

${ }^{11}$ Cadí (en árabe قاضى) es un 'juez' de los territorios musulmanes, que aplica la 'sharia' o código de Derecho musulmán. De la palabra cadí, unida con el prefijo al («el»), provienen las actuales palabras 'alcalde' y alcaide. 
los jardines públicos que embellecen a Córdoba. Quiero aumentarlos y gozar de ellos, como si fueran míos. Me harás prefecto de la ciudad, cuando tú seas Carim $^{12} \ldots$ Y, yo, que era el más amigo del Amir, hoy Almanzor, me eché a reír, diciendo: - ¡En el mundo no se encuentra un muchacho más presuntuoso y necio que tú... cuando llegues a gobernar el Ándalus, haz que me unten con miel y que me paseen montado, al revés, sobre un asno, por las calles de Córdoba...

Tan fanfarrón era que el pariente en cuya casa se hospedaba, hubo de contarnos, al escuchar aquel sucedido, que de noche velaba su despierto soñar de grandezas; y que hasta tal punto estaba obsesionado por esta idea del poder, que un día dijo a su pariente: - Esta noche no he dormido, pensando a quien habré de escoger, para que sea supremo Juez, cuando yo llegue a ser el Rey (Infante, 2012: 35) ${ }^{13}$.

\footnotetext{
${ }^{12}$ Carim o Karim. Nombre masc. de origen árabe con el significado de «el honorable», «el generoso». En el año 991, y para celebrar su fama, Almanzor adoptó el título real de Malik Karim, esto es, Rey Noble.

${ }^{13}$ Cfr. Dozy (1920: 102-105): «En uno de los primeros años del reinado de Alhaquen II, cinco estudiantes comían en un jardín de las inmediaciones de Córdoba. A los postres reinaba gran alegría entre los comensales; sin embargo, uno solo permanecía silencioso y pensativo. Era alto y bien formado; la expresión de su rostro noble, casi altanera, y su actitud revelaba un hombre nacido para el Poder.

Saliendo, al fin, de su abstracción, exclamó de pronto:

- No lo dudéis; yo seré un día el dueño de este país.

Sus amigos se echaron a reír al escuchar esta exclamación; pero el joven prosiguió sin desconcertarse:

- Decidme cada uno de vosotros el cargo que desea, que yo se lo daré cuando reine.

- Pues bien —replicó entonces uno de los estudiantes-; encuentro deliciosos estos buñuelos, y pues te es igual, desearía ser nombrado inspector de mercado, porque entonces tendría buñuelos a todo pasto y sin que me costasen nada.

— Yo — dijo otro - soy muy aficionado a estos higos, procedentes de Málaga, mi país natal. Nómbrame cadí de esta provincia.

— La vista de estos jardines me agrada extaordinariamente —indicó el tercero-; por lo tanto, querría ser nombrado prefecto de la capital.

El cuarto comensal guardaba silencio, indignado de los pensamientos presuntuosos de su condiscípulo.

- A tu vez — dijo este último-, pide lo que quieras.

El aludido contestó, tirándole de la barba:

- Cuando gobiernes a España, miserable fanfarrón, ordena que después de frotarme con miel, para que las moscas y las abejas vengan a picarme, me monten sobre un asno mirando hacia la cola y me paseen así por las calles de Córdoba.

Lanzó el otro una furiosa mirada; pero dominando su cólera:

—Está bien — concluyó-, cada uno de vosotros será tratado conforme a sus deseos. Algún día me acordaré de lo que habéis dicho.

Terminada la comida, se separaron, y el estudiante de los singulares y raros pensamientos volvió a casa de uno de sus parientes por línea materna, donde se alojaba. Su huésped le condujo a un cuartito, situado en el último piso, y procuró entablar conversación con él; pero el joven, absorto en sus reflexiones, no le respondió más que con monosílabos. Viendo que no había medio de sacarle nada, el otro le dejó, deseándole una buena noche. A la mañana siguiente, viendo que no se presentaba a desayunarse y creyéndole todavía dormido, subió a su cuarto para despertarle; pero con gran sorpresa encontró el lecho intacto y al estudiante sentado en el diván, con la cabeza inclinada sobre el pecho.

-Parece que no te has acostado esta noche —le dijo.
} 
Una segunda obra que Infante debió de tener presente en la composición de su drama, aunque con una incidencia infinitamente menor, no es otra que la del alemán Adolf Friedrich von Shack y su Poesía y Arte de los Árabes en España y Sicilia en la estupenda traducción de Juan Valera, según hago referencia en mi edición de Almanzor (Infante, 2012: 78).

Hay que tener presente la controversia surgida en torno a la Historia de los musulmanes de España hasta la conquista de los almorávides (1861) de Reinhardt Pieter Dozy en su contexto. El arabista holandés llevó a cabo su investigación exhaustiva con el deseo de rectificar la obra de José Antonio Conde, titulada: Historia de la dominación de los árabes en España sacada de varios manuscritos y memorias arábigas, publicada póstumamente en Madrid en tres tomos entre 1820 y 1821 , plagada de errores debido a su escaso dominio del árabe, así como también por la fascinación que sentía por la historia de Al-Ándalus, tal como señala María Eugenia Gálvez Vázquez (1996-1997: 74). La reacción española no se haría esperar al considerar la clerofobia ochocentista que, en su opinión, aquejaba a Dozy, por lo que será atacado desde la ideología católica-conservadora, caso de Francisco Javier Simonet Baca, el autor de Leyendas Históricas Árabes $(1858)^{14}$ y de una brillante y erudita Historia de los mozárabes de España en 4 volúmenes (18971903). La misma actitud defensiva y nacional-católica se observa en el Padre Fita, o en el polémico redactor de La Ilustración Católica, Nulema, que con espíritu beligerante arremete contra Dozy y la «mala intención» con que ha tratado la historia de la dominación árabe en España (Sanmartín Bastida, 2002: 77). Otro tanto cabe decir de Francisco Codera y Zaidín, fundador de la escuela moderna de arabistas españoles, si bien su catolicismo no habría de resultar tan tendencioso como para malograr su rigor científico. Y es que en el fondo de esta maurofobia subyace un enfrentamiento ideológico entre liberales y conservadores, por lo que mientras para los primeros la decadencia hispana sería consecuencia de la expulsión de los moriscos, caso de Pascual de Gayangos y Arce, los segundos opinan que tal proceso es más el resultado de la ocupación árabo-musulmana en 711 y sus efectos (Sanmartín Bastida, 2002: 78). Afortunadamente, poco a poco irá imponiéndose la erudición y la investigación científica sin prejuicios ideológicos que vengan a emponzoñar el conocimiento histórico. Julián Ribera, Emilio García Gómez o Joan

—Es verdad -le respondió el estudiante.

- Y ¿por qué has velado?

- Tenía un extraño presentimiento.

- ¿En qué pensabas?

-En el hombre a quien he de nombrar cadí cuando yo gobierne, porque el actual ya se habrá muerto».

${ }^{14}$ Entre estas leyendas, por cierto, se encuentra Almanzor, una leyenda árabe, obra reeditada de manera independiente en Madrid: Ediciones Polifemo, 1986, aunque no tuvo incidencia en la obra teatral de Blas Infante. 
Vernet i Ginés, entre otros ilustres nombres, se mostrarán mucho más imparciales a la hora de examinar los hechos.

El tema o asunto principal del Almanzor de Blas Infante gira en torno a la naturaleza del poder real y, más concretamente, es una crítica al corrompido régimen de la Restauración borbónica. Hay que tener presente, en primer lugar, que Infante era un ferviente discípulo de Joaquín Costa Martínez (18461911), hijo de campesinos pobres y principal representante de la corriente regeneracionista de finales del siglo XIX. En esta filiación intelectual se demuestra, tal como señala Juan Antonio Lacomba, «una común preocupación por el «problema de la tierra» y el «desarrollo pedagógico», entre muchas cuestiones más, así como un idéntico rechazo a la «realidad oligárquica y caciquil» que les ha tocado vivir - y combatir-, les une y relaciona muy estrechamente» (Lacomba, 1994: 82) ${ }^{15}$. Blas Infante, con humildad, se postulará «seguidor» del maestro aragonés. El autor de Colectivismo agrario en España (1898) y Oligarquía y caciquismo como la forma actual de gobierno en España: Urgencia y modo de cambiarla (1901), obra ésta última que constituye una tremenda denuncia del sistema político canovista de la Restauración y en la que formula la necesidad de aplicar en España una verdadera «política quirúrgica», por parte de «un cirujano de hierro, que conozca bien la anatomía del pueblo español y sienta por él una compasión infinita» (Costa, 1982: $105)^{16}$, se mostró siempre partidario de una meritocracia en la que el gobierno «de los peores» quede sustituido por el «de los mejores».

Tengamos en cuenta que en 1921, cuando estaba escribiendo su segunda pieza teatral, Infante acababa de publicar La Dictadura Pedagógica, obra que plantea un nuevo modelo de sociedad universal. Su autor defiende un proce-

${ }^{15}$ Se da además la circunstancia de que Costa también fue notario, tanto en Jaén (1888), como luego en Madrid (1893), siendo también partidario de las ideas republicanas, no tanto por convencimiento como por rechazo a otras opciones políticas. En cualquier caso, téngase en cuenta que fue miembro de la Unión Republicana de Nicolás Salmerón. Infante, por su parte, ingresaría en el Partido Republicano Federal en 1931. En el quinto aniversario de su muerte, con motivo del homenaje que le rindió el Ateneo de Sevilla, Blas Infante habría de dedicarle un opúsculo como muestra de su devoción al aragonés, llegando a compartir plenamente sus planteamientos críticos. Esta es la imagen que Infante nos da de la España de la Restauración, tal se encuentra en Infante (1916: .28) : «Las funciones de cuidar la Patria eran consideradas por los españoles directores o dirigidos [...] como funciones de una natural rapacidad, en las cuales turnaban los partidos gubernamentales y sus miserables clientelas, piezas de un mecanismo fatal, ordenado a extraer la sangre de la nación».

${ }^{16}$ Esta invocación al «cirujano de hierro» del que hablaba Costa para desmontar el caciquismo se ha interpretado demasiadas veces como una alusión a la necesidad de establecer la figura de un dictador ; pero no tanto, lamentablemente, asociada a la persona de un gobernante capacitado que venga a garantizar que todas las instituciones constitucionales del régimen presidencial funcionen: un Parlamento, un Poder Judicial independiente y una Administración eficaz. El General Primo de Rivera se apropió indebidamente de parte del discurso regeneracionista de Costa para justificar su golpe de estado militar en 1923. 
so de renovación de la Humanidad por medio de una decidida labor educativa encaminada a la transformación de una organización social universal regida por pedagogos. Y es que, como señala acertadamente Manuel Hijano del Río (2007: 110):

la obra supone una crítica al modelo de la revolución comunista implantado recientemente en la Unión Soviética, y luego en una claramente diferenciada segunda parte, el planteamiento de un nuevo modelo social resultado de la implantación de la revolución cultural que supone el gobierno de una Dictadura Pedagógica.

El considerable grado de utopía que se advierte en esta obra es lo que la distingue, mayormente, del resto de su producción escrita. Ahora bien, detrás de cada utopía discurre siempre un momento manifiesto de crisis, por lo que resulta imprescindible ser conscientes de la realidad española del momento:

Lo cierto es que el año 1920 representa un hito en el proceso de aumento de las dificultades del mundo obrero español y, alrededor de este año, en el de la negativa relación entre los casi inexistentes esfuerzos de modernización impulsados por el poder y la creciente tensionalidad del medio ambiente, especialmente del urbano (Casassas Ymbert, 1983: 23).

En este contexto histórico apareció publicado el libro, es decir, en tiempos de decadencia de la Restauración borbónica y el bipartidismo imperante en el Estado español. Heredero de las ideas regeneracionistas de Costa, Infante convierte al «cirujano de hierro» en «dictador pedagogo», adoptando además una posición afín en torno a la conformación de una élite dirigente o aristodemocracia, en la que los educadores sustituyan a los políticos, por lo que llega a afirmar sin vacilaciones lo siguiente: «El pueblo vendrá a ser regido por sus hijos mejores, único modo de autogobernarse. Tendremos la forma de gobierno natural: gobierno del pueblo por sí mismo, representado por sus hijos mejores» (Infante, 1921: 33).

Dentro de una honda aspiración a una sociedad sin clases, aquellos hombres más cualificados moral y éticamente son los que deben constituirse en vanguardia dirigente, en «dictadores pedagogos» que vengan a formar el proceso creador del «alma» de la sociedad comunista. En esta ética revolucionaria que debe seguir la nueva sociedad utópica que propugna Infante, encontramos la vieja idea griega del Filósofo-Rey que actuará de acuerdo con los principios generales de «lo bello, lo justo y lo bueno», tal como nos legara Platón (AA.VV., 1997: 26-30) en La República (Libro VII -517a-521b-). Blas Infante hallará en la propia historia de Al-Ándalus, «la única nación antorcha que hoy alumbra al mundo» (Infante, 2012: 62), el modelo para ilustrar la figura de este «dictador pedagogo» en la persona de Almanzor. Veamos cómo.

Nuestro protagonista, el temible caudillo amirí Almanzor (938-1002), se siente irremisiblemente destinado por un sino desconocido a la conquista del poder. Esta idea aparece ya claramente expuesta por el poeta Zaid de Bagdad en el prólogo de la obra: 
Un hombre que nace rey, si encuentra su trono usurpado por otro vasallo, para llegar hasta él, abre resuelto un cauce de sangre...

Y, esto hizo Almanzor, mi noble Rey. ¡Si él hubiera aparecido en el lecho imperial de donde nació llorando el imbécil Califa Hixem, su natural vasallo! Pero los hombres vistieron a éste la púrpura imperial que naturalmente a aquél pertenecía... ¡Infringieron así la augusta ley; cometieron delito de lesa majestad. El delito, precedió, por esto, al castigo de sangre por mi señor decretado! [...].

Para enseñar a los hombres a ser dioses, ofrezcámosles ilustres ejemplos. El amor y el crimen hicieron Rey a Almanzor. El crimen - me dijo un día- sirve para ganar y conservar los tronos. ¿Pero no será por esto un crimen mayor de aquéllos que nacen reyes, el dejar los tronos a los usurpadores? (Infante, 2012: 14)

A pesar de no ser rey por línea de sangre, Almanzor sabe desde muy pronto que por su superioridad espiritual le corresponde el ejercicio del poder fáctico $^{17}$, dejando sólo nominalmente como rey a Hixem II, el Califa ${ }^{18}$, en virtud de una profecía que le advierte de que, cuando la dinastía Omeya termine, se desencadenará la guerra civil. No es, por tanto, de extrañar que se dirija con estas significativas palabras al Príncipe Mohamed, en el pasaje IX, escena II:

¿Podría yo no gobernar? Yo vine al poder para cumplir mi sino ineluctable: la idea de este sino en mí era obsesión. La seguridad de que habría de realizarse me acompañaba siempre. Era toda mi vida interior. Sin haber nacido Rey, desde niño me preparaba para Rey, incendiando mi alma en los hechos ardientes de la Historia antigua, aunque ya no sé si eran las viejas crónicas las que incendiaban mi espíritu o si era este sino que venía a hacer arder sus páginas polvorientas. ¿Quieres tú mandar para esto, Príncipe Mohamed? Sabes halagar al pueblo y, por tanto, lo habrás de tiranizar...Tú serás Califa, cuando yo muera (Infante, 2012: 64).

A causa de su talento natural y fuerte voluntad, el Almanzor de Infante se erige en el gobernante ilustrado o maestro director capacitado para el ejercicio del poder, muy contrariamente al Príncipe Mohamed, quien sólo persigue reinar para su propia satisfacción y vanidad. Así es como en La Dictadura Pedagógica, Blas Infante ya había anticipado su modelo de gobernante para llevarlo luego a escena en su pieza teatral inacabada. No es extraño, en consecuencia, que afirme lo siguiente: «Ellos (dictadores pedagogos) serán los que hasta su realeza elevarán los espíritus de los demás hombres. Ellos en cada hombre tallarán un Rey. Ellos serán los que vendrán a crear la Humanidad Rey, emancipada de toda dictadura» (Infante, 1921: 92-93).

${ }^{17} \mathrm{Y}$ es así como se lo hace saber a su principal oponente o antagonista, el Príncipe Mohamed ben Hixem ben Moawia, primo sobrino del Califa Hixem II y jefe de la conspiración contra Almanzor en la trama de nuestra obra, (Infante, 2012: 62): «Reinar es, en vosotros, una necesidad, no de vuestra superioridad espiritual, sino de vuestros groseros sentidos. ¡Queréis reinar para gozar!».

${ }_{18}$ Almanzor declara abiertamente a su examante, la vascona Sobeya, madre del Califa Hixem II, sus pretensiones, en ese mismo pasaje IX, escena IV, (Infante, 2012: 66): «iEl trono! ¿Para qué quiero yo ese trono de tu hijo, si he de tenerlo en el martirio eternamente vigilante, de la dominación, efectiva?». 
Sería un error considerar a Almanzor como un hombre de ambición desmedida que se vale del populismo y la demagogia para alcanzar el poder, pues viene a encarnar el prototipo del hombre nuevo que aspira por su realeza natural a despertar en los individuos una conciencia colectiva de soberanía social para forjar una Era de transformación. A esta primera lectura crítica realizada por Blas Infante con el ánimo de superar el anquilosamiento del viejo régimen de la Restauración borbónica de su tiempo, se superpone otra segunda lectura muy distinta: la del héroe romántico que se cree capaz de vencer al destino, imponiéndose incluso a las circunstancias adversas, frente al héroe clásico de la tragedia que aprende dolorosamente mediante la anagnórisis que nunca podrá escapar de la suerte que le depara su destino: Edipo rey. Incluso el protagonista romántico del Duque de Rivas en Don Álvaro o la fuerza del sino reconoce finalmente al destino desde una perspectiva clásica ${ }^{19}$,

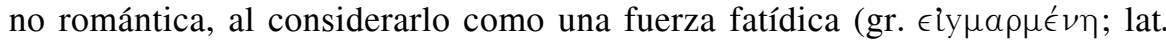
fatum; port. fado; cast. hado), que opera como un poder nefasto en cada una de sus acciones; no así nuestro personaje Almanzor, quien al dirigirse al Califa Hixem II dice lo siguiente : «¿Dónde está un hombre capaz de vencer al Destino? Sólo este hombre pudiera ser Rey, sin manchar la Majestad. En contacto de los hechos que son la trama del Destino, la Majestad padece» (Infante, 2012: 65).

Puede incluso que admitamos que en un ejercicio de supremo egocentrismo, el héroe del drama de Blas Infante, Almanzor, considera a los actos de su propia voluntad como decreto del destino, lo que no hace más que enfatizar su raíz romántica ${ }^{20}$.

Por otra parte, la realidad histórica iba a mostrarle al propio Infante su cara más amarga, en la medida en que le tocó vivir cómo un hombre de ambición desmedida, el General Miguel Primo de Rivera, iba a ejercer — poco tiempo después de la que se presumía como su siguiente obra de inminente aparición en 1921 - , el poder fáctico, con motivo del golpe de estado de 1923 que nació al amparo de la monarquía de Alfonso XIII. ¿Acaso la realidad misma superaba a la ficción, siendo por ese motivo que el autor dejase inconcluso su drama al no querer que su obra pudiera ser interpretada como un panegírico al Dictador? Nunca lo sabremos.

${ }^{19}$ Cicero, De Divinatione, digitalizado por The Latin Library [en línea] http:// www.thelatinlibrary.com/cicero/divinatione1.shtml [Consulta: 28.03.2012] , Liber I, LV, 125: «Fieri igitur omne fato ratio cogit fateri. Fatum autem id apello, quod graeci heimarmene, id est ordinem seriemque causarum, cum causae causa nexa rem ex se gignat. Ea est ex omni aeternitate fluens veritas sempiterna».

${ }^{20}$ Esto se aprecia muy significativamente en las palabras que Almanzor dirige a Sobeya, madre del Califa: «Sobre lo plácido, que son los Palacios del Alcázar; y el recinto dorado y florido de Zahara, sobre el corazón de Almanzor, cuando venga a latir amoroso, reinad vosotros; sobre el torbellino de las pasiones, que se despeñan en los fondos de insondables simas; o que son alaridos entre el estridor de las armas y el fragor de los combates, ¡dejadme reinar a mí!» (Infante, 2012: 66). 
Otro aspecto interesante sobre el que conviene llamar la atención es, sin duda, el motivo de la conspiración que se cierne sobre el protagonista, quien cuenta con dos espías infiltrados entre sus oponentes organizados en Asamblea, el capitán bereber Wanzemar y el poeta Zaid de Bagdad. Dicha conspiración se convierte en el eje principal sobre el que gira la mayor parte de la jornada primera.

Tengamos presente - necesario es repetirlo - que estamos a principios de la década de los 20 del siglo pasado y que Blas Infante ha estado vinculado muy intensamente a la ciudad de Córdoba - lugar sobre el que se desarrolla la acción de su drama y la temática de la conspiración que la envuelve-, en un pasado reciente. Hay, por tanto, elementos autobiográficos que vienen a incidir en el proceso de gestación y creación de su drama Almanzor que no deben ser desatendidos. El 1 de enero de 1919, Infante había redactado el Manifiesto Andalucista de Córdoba, firmando él mismo en primer lugar. Dicho manifiesto se enmarca además en el final de la Gran Guerra (1914-1918) y el enunciamiento por el $28^{\circ}$ presidente de los EE.UU., Thomas Woodrow Wilson, de sus célebres «Catorce Puntos» con el principio de las nacionalidades y su autodeterminación. Fue precisamente en ese momento histórico, particularmente sensible del siglo XX, cuando Infante participó en una conspiración política, según él mismo declara en un momento de su obra titulada: La verdad sobre el complot de Tablada y el Estado libre de Andalucía (1931), tal como se deduce del siguiente pasaje:

la única conspiración revolucionaria andaluza, en la cual he intervenido (la llegué a conocer a última hora) y para la cual hube de redactar el manifiesto, es decir, aquella conspiración desarrollada el año 1919 por nuestro Centro Andaluz de Córdoba y por los amigos inolvidables que en su seno se agrupaban; yo la aprobé y me avine a seguir a los compañeros cordobeses en su aventura frustrada inconscientemente por el Gobierno maurista, porque para mí, Córdoba era y es una garantía de fuerza o de energía brava al servicio de los ideales andalucistas (Infante, 1979: 59).

Infante conocía perfectamente por experiencia propia todos los entresijos que rodean a una conspiración política frustrada, semejante a la que logra adaptar en el ámbito de la ficción en su drama histórico, incluso con la utilización de vocablos propios de la Masonería, caso de «tenida», o el empleo de un santo y seña que sirva a los conspiradores para identificarse: «Imán ausente-Ley presente-Conciencia Alcorán». Entre los diferentes conspiradores que forman parte de los distintos estratos sociales, encontramos la figura misteriosa de un viejo, cuya identidad no se nos descubre, pero que desempeña un papel fundamental en la obra. Dado que desconocemos todavía el contenido de la jornada tercera ${ }^{21}$, poco podemos avanzar al respecto a la hora de indagar más detalles sobre su intervención en la trama, así como conocer el

\footnotetext{
${ }^{21}$ Vid. supra nota 6.
} 
desenlace final del drama incompleto. No obstante, de la lectura de la jornada primera se desprende que dicho personaje, al escuchar el nombre de Mozafi, poderoso ministro de Al-Hakam II —el difunto Califa padre de Hixem II-, reacciona violentamente mandando callar a su interlocutor (Infante, 2012: $51)^{22}$. Si el viejo en cuestión es el propio Mozafi o un fantasma, como parece creer el Capitán Wanzemar, es algo que desconcierta al lector. De ser cierta esta última posibilidad, nos encontraríamos con un drama histórico que incorpora un elemento fantástico.

Por otra parte, la reacción de temor que manifiesta Almanzor ante su presencia al reconocerle y mandarlo luego poner en libertad, no hace más que ahondar en esa última hipótesis, si bien cabe entonces la posibilidad de entrever que acaso el misterioso viejo no sea Mozafi, sino el Príncipe Moghira, hermano de Al-Hakam II, y asesinado por orden del caudillo amirí, quien lo considera desde su remordimiento como «la sombra más negra de mi alma» (Infante, 2012: 66), al representar un obstáculo al acceso de Hixem II al poder real, ya que a la muerte de su padre contaba sólo con nueve años. Nada más puede aportarse hasta el presente sobre la verdadera identidad del personaje del viejo, quien, a pesar de admirar sobremanera a Almanzor, actúa para derrocarle, por lo que ha de permanecer envuelto en medio de sus contradicciones en el ámbito del enigma.

Otro aspecto a resaltar es la prosopopeya o personificación del Salón bajo del Alcázar de Córdoba, alrededor del cual se desarrolla toda la acción de la jornada primera. Esta idea de dotar de cualidades propias de los seres animados al Salón (Infante, 2012: 18-24), no es ajena a la percepción arquitectónica de los árabes, dado que los muros y las paredes escritas hablan al visitante, como podemos contemplar aún en la propia Alhambra de Granada, o incluso en la propia casa de Blas Infante en Coria del Río, Dar al-farah, la Casa de la Alegría, en la medida en que su horror vacui permite esta plasmación en el campo de la arquitectura y las artes decorativas, también con pasajes extraídos del Corán.

El dramaturgo muestra una riqueza de vocabulario admirable sobre la construcción, ofreciendo un conocimiento léxico de arabismos en desuso o muy técnicos que reviven aún en Andalucía (alfarje, aljecería, almorrefas, arrabás, etc.). Otro tanto sucede, aunque en menor cuantía, con la vestimenta (alfaremes, alquicel, alepín, etc.).

Poco después de hablarnos del Salón y contarnos con sus propias palabras

${ }^{22}$ Además, el misterioso viejo muestra una agilidad impropia de su edad esquivando una puñalada del Capitán Wanzemar, al ser reconocido como espía infiltrado de Almanzor en la conspiración, asestándole un golpe en el pecho al bereber con la caña de su báculo, hecho que luego el propio Wanzemar rememora como algo fuera de lo común; todavía más teniendo en cuenta la extraña actitud del propio Almanzor ante las burlas del viejo que ha presenciado, ya que pese a reconocerle, pero sin llegar a revelar su identidad, el caudillo amirí ordenara su libertad, (Infante, 2012: 69). 
las mutaciones que ha ido sufriendo con el paso del tiempo, se entona un auténtico laus Baeticae, en el que el autor va recorriendo las distintas etapas esenciales de la evolución andaluza desde el neolítico, pasando por Tartessos, o las vinculaciones con la Grecia clásica y el ámbito mitológico, hasta el esplendor de Al-Ándalus con la creación de una «nación jardín» que había de deslumbrar a Occidente, dando muestras de una formidable erudición.

En cuanto a la jornada segunda se refiere, ésta desarrolla inicialmente el relato histórico-legendario de la expedición de Almanzor a Santiago de Compostela en 997, dando de nuevo muestras el autor de un gran conocimiento de la arquitectura, al describir con gran precisión técnica detalles de la iglesia derruida. El tema de las ruinas aquí incorporado, si bien era muy grato a los románticos, se encuentra desprovisto de subjetivismo al imponerse la descripción expresionista, muy adecuada al arte románico. Lamentablemente, sólo conservamos un breve fragmento ya que el Manuscrito Almanzor (AAZ) termina de manera abrupta ${ }^{23}$.

La incidencia de lo medieval en el Modernismo dio origen a una modalidad dramática denominada teatro poético que surge a raíz de la penosa situación que atravesaba la escena española de su tiempo. El adalid de dicha corriente teatral que inicia la composición de dramas en verso inspirándose en la Edad Media fue Eduardo Marquina con Las hijas del Cid (1908). Toda una pléyade importante de autores iba a secundarle pronto: Cristóbal de Castro Gutiérrez, Enrique López Alarcón, Ramón María del Valle-Inclán, Francisco Villaespesa y Jacinto Grau, entre otros tantos ilustres nombres. Este teatro histórico modernista de inspiración medieval gozaría de una amplia difusión en el primer tercio del siglo XX.

En la mayoría de estos autores predomina el verso sobre la prosa: léxico preciosista y refinado, artificios retóricos gratos a la estética modernista, arabismos, frecuencia de arcaísmos a fin de reproducir el habla medieval, tanto léxicos como sintácticos, o la variedad métrica que permitía la reconstrucción de estrofas tradicionales son, en definitiva, algunos de los recursos más utilizados por nuestros autores para ambientar la acción dramática de atmósfera

${ }^{23}$ Hay una nota manuscrita en la última cuartilla del Manuscrito $A A Z$, p. 235 a lápiz y que dice así: «Almansur. La escena de Abul Moghira y la querida de Almanzor, con los versos, en las páginas 142 al 144, Tomo I, de Schack». Dicha escena se encuentra efectivamente en el tomo primero de la edición de Schack (1881: 150-153). Aun cuando no se corresponden exactamente las páginas, no cabe duda de que debió ser una edición similar, puesto que además no puede ser otra la escena recreada que la que tiene como protagonistas a Almanzor, una cantadora favorita del Amir y el Principe Moghira. En dicha escena, Almanzor reacciona furioso para después ceder al sentirse rechazado por la muchacha, quien ama al Príncipe y es correspondida por éste recíprocamente. ¿Influyeron los celos de Almanzor en su decisión de asesinarlo a la muerte de su hermano el Califa Al-Hakam II, siendo como era además un obstáculo para sus ambiciones políticas? Recordemos que Almanzor nos dice que para él su muerte era «la sombra más negra de mi alma». 
y asunto medievalizante. Toda esta retórica modernista y los demás elementos que incorporaba el teatro histórico en verso vendrán a ser sistemáticamente parodiados hasta el ridículo por el gaditano Pedro Muñoz Seca en La venganza de don Mendo (1918). Su éxito fue clamoroso, en buena medida debido a la carencia de originalidad de la mayoría de estas obras, lo que explica su vigencia frente a las restantes piezas dramáticas.

No puede negarse, sin embargo, la calidad poético-dramática de obras como Cuento de abril: escenas rimadas en una manera extravagante (1910) de Ramón María del Valle-Inclán, El alcázar de las perlas (1911) del almeriense Francisco Villaespesa - a cuyo estreno en Granada habría de asistir el propio Federico García Lorca, acompañado del pintor Manuel Ángeles Ortiz un 9 de noviembre de ese mismo año en el teatro Isabel La Católica que aún se conserva (Ceba, 1990-1991: 85)—, o, por ejemplo, El Conde Alarcos (1917) de Jacinto Grau Delgado, a quien pese a su fracasada reconstrucción de la lengua medieval castellana hay que reconocerle la enorme belleza y elegancia de su prosa poética (García-Lorenzo, 1970: 398). Estas tres obras junto a las hijas del Cid de Marquina vinieron a constituir un oasis exuberante en el árido panorama de la escena española del momento.

Si nos atenemos a la temática de una gran mayoría de estas obras dramáticas, como Las hijas del Cid, Doña María la Brava y Cantiga de Serrana, de Eduardo Marquina, Gerineldo de Cristobal de Castro y Enrique López Alarcón, Doña María de Padilla de Villaespesa, Blasco Jimeno de Fernando López Martín, Romance de doña Blanca de Luis Fernández Ardavín, Romance de Doña Sol de Rufino Sáez, por citar sólo algunas de las más representativas de su tiempo, vemos como todas coinciden, tal como señala José Manuel Cabrales Arteaga (1989: 21): «en la exaltación de unos valores nacionales, identificados con Castilla. Podría decirse que existe en el teatro poético un adoctrinamiento de índole nacional y colectiva». Efectivamente, las obras susodichas de ambientación medieval y estética modernista incurren en un reiterado laus Castellae (Cabrales Arteaga, 1989: 29), pues no se recrean en otro reino cristiano-medieval que no sea la mitificada Castilla, considerada como la nación constituyente de España, muy en la línea de los autores de la Generación del 98. Sólo unas pocas obras escaparán de este tipificado cliché Castilla-España, recreando, por un lado, el mundo elegante y refinado de una corte provenzal como en Cuento de abril de Valle-Inclán, en oposición a la ruda y primitiva Castilla, de ahí su originalidad temática y rebeldía frente a los postulados más conservadores, caso de Marquina, o bien por otro representando el mundo arábigo-andaluz con toda su carga de sensualidad y exotismo orientalizante tan grato a los modernistas. Es el caso de El alcázar de las perlas o Aben Humeya de Villaespesa como de Flores y Blancaflor de Luis Fernández Ardavín.

Este es, en definitiva, el ámbito del panorama escénico español en que se circunscribe la producción dramática de Blas Infante: Motamid, último rey de Sevilla (1920) y Almanzor circa 1921. Ambas obras pueden incluirse dentro 
del denominado teatro histórico modernista de inspiración medieval en prosa poética. Nuestro autor, a diferencia de la mayor parte de sus contemporáneos, no entonó en sus obras el laus Castellae sino el laus Baeticae conforme a sus creencias al modo de Villaespesa en El alcázar de las perlas, mas con un sentido completamente distinto debido a la conciencia que como intelectual tenía de la función social del teatro y de su capacidad como instrumento educativo, no puramente con una finalidad ornamental y esteticista. El hecho de que su finalidad fuese más de carácter didáctico no implica en modo alguno que descuidase la recreación de la atmósfera arábigo-andaluza y el lenguaje (presencia de arabismos y arcaísmos), en cuanto a la forma se refiere, al modo de los modernistas; pero en cuanto al fondo era más afín a los posrománticos en la medida en que en éstos se advierte «una mayor preocupación por la fidelidad histórica y la exactitud documental» (Cabrales Arteaga, 1989: 28) por relativa que ésta siempre resultase. En cualquier caso es verificable la influencia que el teatro poético modernista de otros autores contemporáneos - y no sólo Villaespesa por su temática-, ejerció sobre la obra dramática de Infante y, más concretamente en su Almanzor, objeto aquí de mi atención. Las similitudes estilísticas que se reconocen en alguna de las acotaciones de El Conde Alarcos de Jacinto Grau en cuanto a la descripción de la Infanta se refiere, sin duda el personaje más rico de la tragedia como mujer altiva, orgullosa, vengativa y soberbia, tal como a continuación ofrezco:

Sale de su cámara la Infanta, apareciendo como envuelta en fuego, ataviada con el rojo brial del primer acto; sueltos y caídos por la espalda, cual penachos de llamas, los ensortijados cabellos bermejencos. El rostro, de un pálido blanco mate, y los oscuros ojos, relumbrantes de fiebre, por negras ojeras agrandados, conviértenla en viva imagen de una vida vacía en el deseo terco y profundo de esa locura obstinada sólo a la muerte rendible. (Escena II, Acto 3º) (García Lorenzo, 1970: 399).

No distan en demasía sino que más bien guardan un estrecho paralelismo con otra de las acotaciones de Almanzor de Blas Infante a la hora de describirnos a su personaje principal, hombre igualmente altivo, orgulloso, más ambicioso que vengativo, pero igualmente soberbio:

Sus ojos son negros y profundos; de mirar acerado a veces; y otras, plenos de jugosas efusiones. Correctas la nariz y la boca; negros los cabellos, de los cuales algunos rizos azulados, no sujetos por el turbante, caen sobre sus pálidas mejillas. Cubre su cabeza con un turbante verde, de cuyo centro surge la convexidad de un casco de oro; y envuelve el cuerpo en un amplio manto blanco, el cual al abrirse, deja ver su mano derecha apoyada sobre el puño repujado con piedras preciosas, de una espada cristiana, pendiente de un lujoso tahalí. Calza unos rojos borceguíes flexibles, los cuales rematan, posteriormente, en doradas espuelas. (Pasaje IX , jornada I) (Infante, 2012: 61).

En ambos casos, tras su lectura, nos sentimos tentados a creer que estamos quizás ante dos de entre los más hermosos fragmentos de la prosa modernista del primer tercio del siglo XX llevada al teatro. 
Parece extraño, teniendo en consideración la importancia de su autor, que Blas Infante no haya merecido ni un solo comentario en la tan voluminosa como magnífica Historia del Teatro Español (2003) dirigida por el Profesor Javier Huerta Calvo, mas lo cierto es que no existe mención alguna de su obra Motamid, último rey de Sevilla, y no digamos ya de Almanzor. Tampoco tenemos constancia de que haya sido objeto de un serio estudio literario de conjunto, cosa que debemos achacar a su escasa difusión, y menos aún que su drama histórico haya sido alguna vez representado, tanto en vida de su autor como posteriormente. Es cierto que su obra teatral, la única completa que conservamos, apareció en un momento de crisis de la escena española en los años de la posguerra europea y por un autor novel. Recordemos a este respecto las palabras de Ramón Pérez de Ayala (1963: 524-525):

Es justo que el público deserte de los teatros e invada cinematógrafos, circos y music-halls, pues en puridad una película afortunada, un clown dotado de fantasía grotesca o una bailarina hermosa...,suscitan sensaciones de orden estético más complejas y genuinas, más dinámicas, más modernas que la mejor pieza teatral.

A pesar del contexto adverso en que parece iniciarse el teatro de Blas Infante en la década de los 20 , lo cierto es que ya en el prólogo monologal de su obra Almanzor incorpora elementos innovadores en su teatro - aun tratándose de un drama histórico de regusto romántico-, al dirigirse a los espectadores el personaje - Zaid de Bagdad-, y producir esa peculiar interacción con el público que dentro de la concepción moderna del teatro iba a resultar luego absolutamente renovadora y vanguardista en la obra de Luigi Pirandello, Sei personaggi in cerca d'autore, estrenada en Italia en 1921 y en España por primera vez en el teatro Goya de Barcelona, el 19 de diciembre de 1923, en versión castellana (Camps, 1996-1997: 30).

Todo drama histórico comporta en mayor o menor medida una idealización de lo real, puesto que parte de unos hechos conocidos ambientados en un pasado, más o menos remoto, cuyo tratamiento estético depende de las estrategias literarias utilizadas por su autor. En el caso del Almanzor de Blas Infante podemos afirmar que se trata de un drama histórico modernista de clara filiación romántica no sólo por su ambientación medieval y su maurofilia literaria, grata a la sensibilidad romántica, o por tener como eje vertebrador la problemática del hombre consigo mismo y su destino, sino también por la manera con que pretende provocar el efecto y la sorpresa en el público asistente. Tengamos, por ejemplo, en cuenta, que el héroe no aparece inicialmente, sino que se va manteniendo una progresiva intriga, es decir, un in crescendo en torno a su figura típicamente romántico. Es así como el personaje de Almanzor no aparece hasta el ultimo pasaje o pasaje IX de la jornada primera. Todo esto concuerda perfectamente con la puesta en escena romántica, dado que, como subraya, Montserrat Ribao Pereira (1999: 231): 
Rara vez el protagonista aparece en las primeras escenas de la pieza; antes bien, se le presenta, anuncia, o da de él diferentes versiones...; en definitiva: se crean expectativas diversas para que su entrada posterior sea lo más estelar posible. Ello se consigue cuidando el modo de irrupción (enmascarado, embozado, disfrazado...) y el punto por el que la lleva a cabo, generalmente el foro, convertido así en un espacio connotado por el efectismo al que se asocia, y que coloca los episodios más relevantes de la obra en la mejor de las perspectivas posibles para el público.

Afirmaba el gran dramaturgo de nuestra posguerra, Antonio Buero Vallejo (1981: 19), que «escribir teatro histórico es reinventar la historia sin destruirla», y eso es precisamente lo que hizo Blas Infante en su teatro poético modernista de temática andalusí e inspiración romántica, tanto con su Motamid, como con Almanzor, en la medida en que son adaptaciones teatrales bastante fieles de la historiografía decimonónica, la Historia de los musulmanes de España hasta la conquista de los almorávides de Reinhardt Pieter Dozy, en nuestro caso, pero que contienen elementos puramente ficcionales, dado que ambas figuras dramáticas, el rey sevillano y el hagib cordobés, son además portavoces de la cosmovisión del autor. No en balde se puede afirmar que más allá del esteticismo propio de las piezas dramáticas de los modernistas reconocemos en el teatro histórico de Blas Infante una honda raíz romántica, en la medida en que el teatro romántico operaba desde el plano de las ideas que venían a encarnar sus personajes principales condicionando así su conducta, como muy bien describe José Yxart y Moragas en El Arte escénico en Espa$\tilde{n} a$, vol. I (1894), mediante el siguiente fragmento:

Lo que distinguió, por de pronto, a los personajes del teatro romántico fue su anormalidad. Pretendían ser extraordinarios, como todo tipo artístico, y más que tales eran excéntricos, lo cual es muy diferente. Fatales o malditos, héroes o demonios, escépticos u optimistas, todos hacen consistir su grandeza en la monstruosidad, en la pugna y batalla con el buen sentido ajeno. Por aquí otra cosa los distingue: el carácter de sus móviles...Aquellos héroes se movían a impulsos de ideas y teorías generales con arreglo a cierta filosofía moral, lírica si así puede decirse, esto es, subjetiva, orgullosa, declamatoria, afanosa de mostrarse original en cada accidente de la vida [...] No eran, por ejemplo, enamorados: eran el amor, tal como lo ha hecho la incredulidad o la fe o la ciencia o las luchas del siglo; tal como lo concebía el autor. No eran ambiciosos: eran la ambición, dado nuestro estado social o las aspiraciones de ésta u otra teoría. En una palabra, lejos de ser apasionados, representaban las pasiones en estado lírico todavía (Navas Ruiz, 1990: 128-129).

Dada la condición de intelectual de nuestro autor, sus personajes habrían de acomodarse a sus ideas entrando en conflicto con las de la sociedad andaluza a la que se dirigía, con el ánimo vital de agitar su conciencia y orientarla así hacia su finalidad didáctica principal: mostrarle «el ideal andaluz» en sus más vivas esencias recreado y encarnadas en dos de sus representantes más sublimes de su historia: el rey Motamid y el hagib Almanzor.

Es así como, en definitiva, dentro de la tipología del drama histórico propuesta por Elfriede Neubuhr, Almanzor, así como Motamid, pertenecen al 
segundo tipo, es decir, el «drama de interpretación histórica» que presenta material histórico y lo interpreta, en los términos expresados por Kurt Spang a propósito de esta estudiosa germana: «la autora lo caracteriza como drama a través del cual se plasma la concepción de la historia del autor, bien reflejada en episodios específicos, o bien a través de una visión global» (Spang, 1998: 33).

Ese mundo intrincado de pasiones, ambiciones y conspiraciones ambientado en la Córdoba Califal en que nos sumerge Blas Infante con su Almanzor y el eco de nostalgia que se percibe ante el glorioso pasado de Al-Ándalus, era objeto de recreación literaria por parte de su autor a comienzos de la década de los 20, con la intención de llevar quizá algún día a las tablas su obra dramática. No sabemos qué le detuvo en su composición inacabada, o si el destino quiso que nosotros dejáramos volar libre la imaginación y reinterpretáramos con él, hoy, una de las páginas más brillantes de la historia de Andalucía. Lo único cierto es que, lejos de la realidad vulgar, pacata, monótona y homogénea que imponía el gusto burgués en la escena española de aquel tiempo, este incipiente teatro de Infante representaba una posibilidad distinta, próxima a las preocupaciones y exigencias que expresaba por entonces D. José Ortega y Gasset: «No admitamos que la boca del telón abra ante nosotros su gran bostezo para hablarnos de negocios, para repetir lo que en su pecho y en su cabeza lleva el público: sólo nos parecerá aceptable si envía hacia nosotros bocanadas de ensueño, vahos de leyenda»(Ortega y Gasset, 1963: 312-313).

\section{BIBLIOGRAFÍA CITADA}

AA.VV. (1997). Platón: La República, Libro VII, trad. José Manuel Pabón y Manuel Fernández-Galiano, València: Servei de Publicacions Universitat de València, Col. Educació. Materials de Filosofia.

Buero Vallejo, Antonio (1981). «Acerca del drama histórico», Primer Acto: Cuadernos de Investigación Teatral, 187, pp. 18-20.

Cabrales Arteaga, José Manuel (1989). «El teatro histórico modernista de inspiración medieval», Cuadernos de Filología Hispánica, 8, pp. 11-35.

Camps, Assumpta (1996-1997). «Luigi Pirandello en Cataluña: la razón de una incompresión», Revista de Lenguas y literaturas catalana, gallega y vasca, 5, pp. 29-40.

Casassas Ymbert, Jordi (1983). La Dictadura de Primo de Rivera (1923-1930). Textos. Barcelona: n. ${ }^{\circ}$ 2, Anthropos: Editorial del Hombre. Col. Historia, Ideas y Textos.

Ceba, Juan José (1990-1991). «Influencia de Villaespesa en la obra de Federico García Lorca», Boletín del Instituto de Estudios Almerienses. Letras, n. ${ }^{\circ}$ 9-10, pp. 81-110.

Centro de Estudios Andaluces: Colección de manuscritos de Blas Infante [en línea] Junta de Andalucía, Sevilla, http://maa.centrodeestudiosandaluces.es/biblio/imagendoc/ 00007001_00007500/00007347/00007347_090h0101.PDF [Consulta: 10.01.2012].

Centro de Estudios Andaluces: Colección de manuscritos de Blas Infante [en línea], Sevilla: Junta de Andalucía, http://centrodeestudiosandaluces.es/biblio/imagendoc/ 00006501_00007000/00006911/00006911_090h0101.PDF [Consulta: 9.02.2012]. 
Cicero, Marcus Tullius, De Divinatione, digitalizado por The Latin Library [en línea] http:/ /www.thelatinlibrary.com/cicero/divinatione1.shtml [Consulta: 28.03.2012].

Costa Martínez, Joaquín (1982). Oligarquía y caciquismo como la forma actual de gobierno en España: Urgencia y modo de cambiarla, Tomo I, Zaragoza: Guara Editorial.

Dozy, Reinhart Pieter (1920). Historia de los musulmanes de España hasta la conquista de los almorávides, Tomo III, trad. del francés por Magdalena Fuentes, ( $1^{\mathrm{a} e d i c}$.). Madrid: Edit. Calpe. Col. Universal.

Gálvez Vázquez, María Eugenia (1996-1997). «Almanzor, un héroe andalusí», Philologia Hispalensis. 11, n. $^{\circ} 1$, pp. $73-83$.

García-Lorenzo, Luciano (1970). «Una reivindicación necesaria: Jacinto Grau», Actas del Tercer Congreso Internacional de Hispanistas: celebrado en México D. F., del 26 al 31 de agosto de 1968 (coord. por Carlos H. Magis), México: El Colegio de México, pp. 389-401.

Hijano del Río, Manuel (2007). «La dictadura pedagógica y las ideas educativas en el ideario político del regionalismo andaluz (1916-1936)», en Historia Caribe. Vol. IV, 12, Universidad del Atlántico de Barranquilla: Departamento de Historia de la Facultad de Ciencias Humanas de la Universidad del Atlántico (Barranquilla-Colombia), pp. 107-117.

Huerta Calvo, Javier (Dir.), (2003). Historia del Teatro Español. Vol. «Del siglo XVIII a la época actual». Madrid: Editorial Gredos.

Infante Pérez, Blas (1916). La obra de Costa. Sevilla: Imprenta de J. L. Arévalo.

Infante Pérez, Blas (1921). La Dictadura Pedagógica, Sevilla: Biblioteca Avante.

Infante Pérez, Blas (1976). El Ideal Andaluz, estudios preliminares de E. Tierno Galván y J. A. Lacomba, Madrid: Tucar Ediciones, S.A., —reedición de la $1^{a}$ edic. de Sevilla: Biblioteca Avante, 1915, aunque mutilado hasta en 13 capítulos-.

Infante Pérez, Blas (1979). La verdad sobre el complot de Tablada y el Estado libre de Andalucía, (2 ${ }^{\mathrm{a}}$ edic.). Granada: Edit. Aljibe. Col. Andalucía Libre.

Infante Pérez, Blas (1983a). «Nueva lírica y su influencia en Andalucía» (Andalucía, n. ${ }^{\circ} 174$, año V, Córdoba, 6-I-1920), en Blas Infante, Antología de textos, selección, introducción y notas por Manuel Ruiz Lagos, Sevilla: Fundación Blas Infante.

Infante Pérez, Blas (1983b). Motamid, último Rey de Sevilla, Sevilla: Fundación Blas Infante, Grupo Editorial Sur, 1983 — reedición de la $1^{\text {a }}$ edic. de Sevilla: Biblioteca Avante, 1920 -.

Infante Pérez, Blas (2008). Andalucía. Teoría y Fundamento Político, Manuel Pimentel y Antonio Manuel (eds.), (1 a edic.). Córdoba: Edit. Almuzara, S.L. Col. Andalucía, Serie Pensamiento Andaluz.

Infante Pérez, Blas (2012). Almanzor (ed. a cargo de Josep Esquerrà i Nonell), ( $1^{\mathrm{a}}$ edic.). Kragujevac: Centar slobodarskih delatnosti.

Iniesta Coullaut-Valera, Enrique (1981). «Blas Infante, Historia de un andaluz, Primera Parte» en AA.VV., El Siglo de Blas Infante, 1883-1981. Alegato frente a una ocultación, (Coord. Antonio Zoido). Sevilla: Biblioteca de Ediciones Andaluzas, S. A., pp. 21-71.

Iniesta Coullaut-Valera, Enrique (1989). Los inéditos de Blas Infante. Sevilla: Fundación Blas Infante.

Iniesta Coullaut-Valera, Enrique (1998). «Al-Ándalus en Blas Infante», Pliegos de Encuentro Islamo-Cristiano, 23, pp. 1-48.

Lacomba Abellán, Juan Antonio (1994). «Costismo y andalucismo. La influencia de Joaquín Costa en Blas Infante», Anales de la Fundación Joaquín Costa, 11, pp. 77-84.

Navas Ruiz, Ricardo (1990). El Romanticismo Españo. Madrid: ediciones Cátedra, S.A. Col. Crítica y estudios literarios.

Ortega y Gasset, José (1963). «Meditación del marco»(1921), en Obras Completas. Vol. ( $6^{a}$ edic.). Madrid: Revista de Occidente.

Pérez de Ayala, Ramón (1963). «La crisis teatral» (1927), en Obras Completas, III. Madrid: Edit. Aguilar. 
Ribao Pereira, Montserrat (1999). Textos y Representación del Drama Histórico en el Romanticismo Español, ( $1^{\text {a }}$ edición) Pamplona: Ediciones Universidad de Navarra, S.A., (EUNSA). Anejos de RILCE, n. ${ }^{\circ} 29$.

Sanmartín Bastida, Rebeca (2002). Imágenes de la Edad Media: La mirada del Realismo, ( $1^{\text {a }}$ edic.). Madrid: CSIC.

Sergi, Giuseppe (2001). La Idea de Edad Media: entre el sentido común y la práctica historiográfica, ( $1^{\mathrm{a}}$ edic.). Barcelona: Editorial Crítica, S. L. Col. Biblioteca de bolsillo.

Schack, Adolf Friedrich de (1881). Poesía y Arte de los los Árabes en España y Sicilia, Tomo Primero, traducción del alemán por Juan Valera, ( $3^{a}$ edic.). Sevilla: Fco. Álvarez y Cía. Editores.

Simonet, Francisco Javier (1858). Leyendas Históricas Árabes ( $1^{\mathrm{a}}$ edic.). Madrid: Imprenta Martínez.

Spang, Kurt (1998). El Drama histórico. Teoría y Comentarios. Pamplona: Ediciones Universidad de Navarra, S.A., (EUNSA). Anejos de RILCE, n. ${ }^{\circ}$ 21, Serie Apuntes de Investigación sobre Géneros literarios, n. ${ }^{\circ} 3$.

Fecha de recepción: 26 de abril de 2012

Fecha de aceptación: 11 de octubre de 2012 